\title{
Eine weitere Erfahrung über den Werth der Liebig'schen Suppe $\left.{ }^{*}\right)$; von Dr. Ladwig Walther.
}

In unserem, rärztlichen Intelligenzblatte- vom 5. März laufenden Jahres hat Herr Hofrath Dr. Hecker eine Erfahrung über die Liebig'sche Suppe für Säuglinge mitgetheilt. Erlauben Sie mir, verehrter Herr Collega, Ihre Aufmerksamkeit nochmals auf diese Erfindung v. Liebig's lenken zu dürfen.

Dieses Mal handelt es sich bei Anwendung der Suppe nicht um einen Säugling, sondern um ein durch einen lange andauernden Typhus in seiner Ernährung sehr heruntergekommenes, durch fortdauerndes Erbrechen der sonst sehr leicht verdaulich scheinenden Nahrungsmittel im höchsten Grade geschwïchtes junges Mädchen von dreizehn Jahren. Gewöhnliche Fleischsuppe, Kuhmilch, Bier, Wein, Kaffee Alles ohne Ausnahme wurde von der Kranken stets, ja selbst Wasser wurde sehr häufig noch in der sechsten Woche des Typhus, der während seiner ganzen Dauer mit entschiedenem Keuchhusten einherging und in dessen Folge sich ein bedeutender, über einen Schoppen gutartigen Eiters enthaltender Abscefs zwischen dem rechten Schulterblatte und der Wirbelsäule gebildet hatte, ausgebrochen. Die Kranke war dem Tode durch Erschöpfung nahe, die Abmagerung derselben war in so hohem Grade, wie ich sie kaum bei einem an Lungentuberculose Verstorbenen jemals beobachtet habe, vorhanden, der Puls war ungleich, sehr beschleunigt, ganz leer, die Diarrhöe dauerte noch an, kurz die Kranke bot das Bild einer in der kürzesten Zeit Sterbenden dar; dabei, wie erwähnt, Erbrechen alles Genossenen.

*) Aus einem Schreiben an die Redaction des Münchener „ärztlichen Intelligenzblatts, Nr. 12, 1866", in welchem auch Herrn Hofrath Hecker's Aufsatz abgedruckt ist. Der von Dr. Walther, einem der ausgezeichnetsten practischen Aerzte Münchens, beschriebene Fall ist merkwürdig genug und ohne $\mathrm{Zweifel} \mathrm{für} \mathrm{viele} \mathrm{Aerzte} \mathrm{in}$ weiteren Kreisen von Interesse.

J. $\boldsymbol{L}$. 
Ich entschlofs mich daher, der Kranken die Li ebig'sche Suppe, welche ich schon häufig bei in ihrer Ernäbrung sehr heruntergekommenen Kindern mit dem besten Erfolge gegeben, verabreichen zu lassen, und mein Beginnen war von dem schönsten Erfolge gekrönt. Die ersten drei Löffel der Malzsuppe wurden nicht ausgebrochen; ich konnte sogleich die Gabe dieses Nahrungsmittels vermehren und nach acht bis zehn Tagen war ich so weit gekommen, dafs unter sichllicher Zunahme der Körperfülle, obwohl bei noch fortdauerndem Fieber der Kranken, ungefähr eine Mafs Milch in der Malzsuppe genossen und auf das Beste veriragen wurde, indem nach und nach die Diarrhōe sich verminderte und endich hothige Stuhle sich einstellen. Dabei ist anzufüren, dafs die Kranke auch jetzt noch täglich drei Mal eine grofse Portion dieses Malzbreies mit grofser Begierde und holem Genusse zu sich nimm, obwohl dieselbe nun in vollster Reconvalescenz sich befindet; gebratenes Fleisch und elwas Wein mit gutem Appetit geniefst. Neben der Malusuppe erhiell die Kranke alle $\mathbf{2}$ wei Stunden swei Efsioflel voll von dem Infusum carnis salikum, einem elienfalls von Hrn. v. Liebig empfohlenen Arznei- und Nahrungsinittel.

Ich halte die Sache für wichtig genug, um meine verehrten Herren Collegen hiermit auf die Malzsuppe bei typhösen Krankheitsvorgangen aufmerksam zu machen, da meinesWissens bis jetzt dieses Nahrungsinittel bei derartigen Erkrankungen nicht gegeben warden ist. Den öfter gehörten Yorwurf der Umständlichkeit bei Anwendung des Breies hat schon Hr. Hofrath Dr. Hecker in oben erwahnten Aufsatze grüdlich widerlegt, ich füge nur noch hei, dafs in den Apotheken Münchens die Mischung von Malz und Waizenmehl mit der nothwendigen Menge Alkali in einzelnen Paketen abgewogen sich vorräthig befindet, und dafs das Kochen des Breies eben so wenig Umstände macht, als das einfache Sieden der Milch. Aufserdem ist das Mittel sehr wohlfeil und daher auch für die Armenpraxis ganz leicht einzufübren. 